\title{
Particle Shape Characterization and Laser Light Scattering Measurements of Pharmaceutical Materials
}

\author{
L. M. DiMemmo, ${ }^{*}$ B. Crooks, ${ }^{* *}$ J. Hilden, ${ }^{*}$ C.-Y. Lin, ${ }^{* *}$ G. Young, ${ }^{*}$ B. Sarsfield* \\ * Bristol-Myers Squibb Company, 1 Squibb Drive, New Brunswick, NJ 08903-0191 \\ ** Drexel University, 245 N. $15^{\text {th }}$ Street, Philadelphia, PA 19102
}

Effective communication among scientists of different disciplines is essential for the development of a pharmaceutical drug product. Pharmaceutical formulators, process chemists and analytical scientists all use microscopes to examine particles and often use different terms to describe similar materials. Therefore, it is critical to have terms that convey the same picture to everyone when describing the features of a given material. The first objective of this work was to address this issue by creating a reference for particle shape terminology so that describing particle shape would be consistent. Other objectives were to design an optical microscopy test to monitor particle shape and to provide examples of how particle shape can be used with laser light scattering (LLS) data to provide more information about a material.

The terms selected for particle shape characterization were organized into six categories including morphology, degree of association, particle edges, particle defects, surface characteristics and optical properties [1-2]. A simplified set of axial dimension descriptors to describe particle shape were developed. Although the use of axial dimensions to describe particle shape has been reported in the literature, the axial dimension system presented here is a two step approach using axial dimension ratios and well defined ranges to provide consistency in the descriptors used for several particle shapes [3].

LLS instruments measure angle and intensity of light diffracted off the surface of a particle. The algorithms used to calculate a particle size distribution from a powder often assume that the particles are spherical. As a result, particle shape can affect LLS data. Many times a question about particle shape or particle size arises after material has been consumed for particle size analysis by LLS. Therefore, this test was developed especially for data collection of particle shape on samples that would be analyzed for particle size by LLS. Examples are provided to demonstrate how particle shape characterization can be used to explain and support LLS data. Ultimately, by understanding particle shape and using it in combination with particle size the performance of a material may be better understood.

\section{References}

[1] USP 27, NF 22, United States Pharmacopeial Convention, Inc., Rockville, MD, <776>, (2004). [2] http://www.mineral.galleries.com/minerals/crystal.htm: Descriptive Crystal Habits.

[3] Aldrich, D. Scott, Smith, Mark A.: Applied Spectroscopy Reviews, 34(4), 275-327, (1999). 


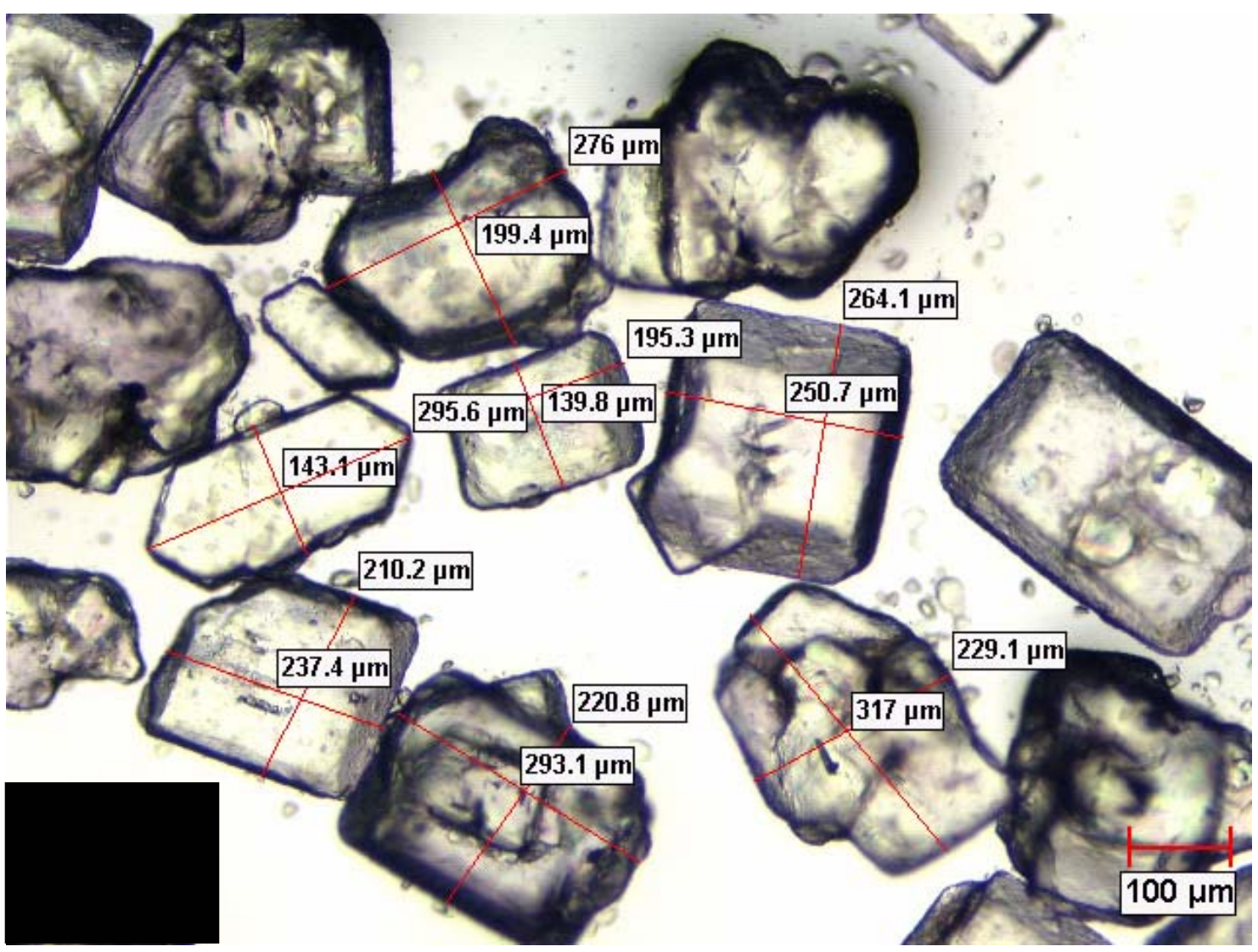

Figure 1. Optical microscope image of particles showing measurement of axial dimensions.

TABLE 1. Axial Dimension Ratio of Particles in Figure 1

\begin{tabular}{lll}
\hline Width (microns) & Length (microns) & $\begin{array}{l}\text { Axial Dimension Ratio } \\
\text { (width:length) }\end{array}$ \\
\hline 199 & 276 & $1: 1$ \\
140 & 195 & $1: 1$ \\
143 & 296 & $1: 2$ \\
210 & 237 & $1: 1$ \\
221 & 293 & $1: 1$ \\
251 & 264 & $1: 1$ \\
229 & 317 & $1: 1$ \\
\hline
\end{tabular}

